\title{
Tri-band MIMO Antenna for WLAN, WiMAX and Defence System \& Radio Astronomy Applications
}

\author{
K. Vasu Babu ${ }^{1}$ and B. Anuradha ${ }^{2}$ \\ ${ }^{1}$ Vasireddy Venkatadri Institute of Technology, Dept. of ECE, Andhra Pradesh, India \\ ${ }^{2}$ Sri Venkateswara University, Tirupati, Dept. of ECE, Andhra Pradesh, India \\ E-mail: vasubabuece@gmail.com
}

\begin{abstract}
In this paper, an efficacious and impermeable undeviating MIMO consisting of $70 \times 50 \times 0.4 \mathrm{~mm}^{3}$ is used for WLAN, defence system \& radio astronomy and WiMAX applications. In place of the technique of parasitic elements to abandon the reactive coupling connection between the antennas we have used an alternate technique where a neutralizing line is connected between the two symmetrical radiating elements. In this technique four small slits of small size are etched on to the ground plane to reduce isolation (mutual coupling) between the antennas. This has resulted in the proposed antenna producing a good bandwidth at the three resonant frequencies of (3.2-3.7 $\mathrm{GHz}$ ) for Wireless LAN, (5.1-5.6 GHz) WiMAX and (6.7$7.5 \mathrm{GHz})$ defence system \& radio astronomy applications with $\left|\mathrm{S}_{11}\right|<-10 \mathrm{~dB}$ and mutual coupling $\left|\mathrm{S}_{12}\right|<-20 \mathrm{~dB}$ for the entire operating band. The simulation results and measured results demonstrate that tri-band MIMO antenna is more acceptable for the design in portable device applications.
\end{abstract}

\section{Introduction}

The multiple-input-multiple-output (MIMO) antenna is a popular antenna in recent times to exchange the data and enhance the rate of data transmission without additional power requirement and spectrum. This MIMO antenna reduces the capacity of the channel transmission and multipath fading. Numerous method of designs consist triband antenna as well as dual-band representation antennas appropriate for WiMAX, Wireless LAN, Bluetooth, DCS and LTE applications have been reported [1-27]. In [1], a $70 \times 50 \mathrm{~mm}^{2}$ compact printed UWB antenna with two notched stop bands was designed for WiMAX \& Wireless LAN applications with a return loss, $\left|\mathrm{S}_{11}\right|<-35 \mathrm{~dB}$. A low-profile dual-band filtering microstrip patch antenna and its application to LTE MIMO system of $90 \times 60 \mathrm{~mm}^{2}$ with operating band from $2.5-2.6 \mathrm{GHz}$ with a return loss, $\left|\mathrm{S}_{11}\right|<-37 \mathrm{~dB}$ was proposed in [2]. A compact Multiple Input Multiple Output slot antenna for UWB applications represent [3]. Here the dimensions of the related antennas were $60 \mathrm{~mm} \times 70 \mathrm{~mm}$, at this dimension the antenna resonate at $3.54 \mathrm{GHz}$ frequency of the operation. For the different areas of wireless communication systems include WLAN, UMTS and WiMAX uses in portable devices. The Several designs of Multiple Input and Multiple Output (MIMO) have been proposed [4-6]. The MIMO antenna system uses especially in Ultra Wide Band (UWB) system provide high data rate of channel capacity. It is also used for multipath fading giving better immunity in comparison to that of narrow- band systems [7]. In [8], a MIMO antenna with portable devices in UWB applications consists of a band-notched characteristic with an overall size of $80 \times 75 \mathrm{~mm}^{2}$ to reduce the isolation $-35 \mathrm{~dB}$ in the resonating band of frequencies at $5.2 \mathrm{GHZ}$ is used. Two metal strips that consists of $\lambda / 3$ and $\lambda / 4$ of length are used on the antenna in [9], Y-shaped MIMO antenna with defected ground structure for the applications design of UWB antenna in [10], Isolation enhancement with the help of two defected ground structures in [11], By inserting meandered feeding lines are arrange to placing in between the UWB MIMO antenna gets dual-polarised in [12], By inserting parasitic elements between the antennas to minimize the isolation effect for mobile terminal applications in [13]. Printed MIMO-antenna system is using neutralization-line technique was proposed for wireless USB-dongle applications in [14] with an overall size of $85 \times 65 \mathrm{~mm}^{2}$ with resonant frequency $2.4 \mathrm{GHz}$. The design of UWB MIMO antennas for portable devices, with band notch characteristics, high isolation and meander feeding lines was proposed in [15-18]. The design of compact MIMO antennas for enhances isolation, improving the isolation performance, MIMO parameters, dual polarization consists in USB dongle applications and metamaterial concepts proposed in [19-23]. A dual polarized ultra wideband Multiple-Input Multiple-Output antenna is divided by the two antenna elements which greatly minimize the overall dimension of the MIMO antenna system to reducing the isolation $-32 \mathrm{~dB}$ in [24]. In [25], the EBG structure was proposed to reduce the effect of mutual coupling between terminals of the antennas. The range of frequency from 2.0 to $2.5 \mathrm{GHz}$ the design resembles an impedance bandwidth of $22.22 \%$ maintain a mutual coupling of $\left|\mathrm{S}_{12}\right|<-30 \mathrm{~dB}$ is observed. A compact dual-band U-shaped planar inverted F-antenna have a low dielectric constant of FR-4 substrate with EBG structure in [26] was found the MIMO parameters like Total Active Reflection Coefficient (TARC) of -7.17 dB PIFAs with EBG and without EBG is $5.65 \mathrm{~dB}$. Finally, a MIMO antenna with wide-band width consists novel type two bent slits is inserted in design of two patches to reduce the isolation and improve the return loss in the entire band of resonant frequencies was proposed in [27]. An inclusive 
contrast of recently prefer dual-band antenna \& tri-band antennas shown properly in the Table 1 .

Table 1: Similarity with other existing methods

\begin{tabular}{|c|l|l|l|l|l|}
\hline $\begin{array}{l}\text { Published } \\
\text { Literature }\end{array}$ & $\begin{array}{l}\text { Total } \\
\text { occup } \\
\text { ied } \\
\text { size } \\
\left(\mathrm{mm}^{2}\right)\end{array}$ & $\begin{array}{l}\text { Band- } \\
\text { width } \\
(\mathrm{GHz})\end{array}$ & $\begin{array}{l}\text { Isolat } \\
\text { ion } \\
(\mathrm{dB})\end{array}$ & $\begin{array}{l}\text { Retur } \\
\text { n loss } \\
(\mathrm{dB})\end{array}$ & $\begin{array}{l}\text { Efficie } \\
\text { ncy } \\
(\%)\end{array}$ \\
\hline$[2]$ & 5400 & $2.0-8.0$ & -37.2 & -35 & 75 \\
\hline$[6]$ & 5600 & $3.1-10.6$ & -39 & -38 & 73 \\
\hline$[9]$ & 4908 & $2.0-10.0$ & -52.4 & -41 & 82 \\
\hline$[10]$ & 4200 & $3.0-10.6$ & -31.2 & -37 & 81 \\
\hline$[12]$ & 4800 & $3.0-10.6$ & -35.8 & -43 & 84 \\
\hline$[18]$ & 3200 & $2.0-8.5$ & -46 & -34 & 74 \\
\hline $\begin{array}{c}\text { Proposed } \\
\text { antenna }\end{array}$ & 3500 & $2.0-8.0$ & -58 & -49 & 89 \\
\hline
\end{tabular}

\section{Antenna Configuration and Design Approach}

The proposed tri-band MIMO antenna is shown in Fig.1 with a compact size of $70 \times 50 \times 0.4 \mathrm{~mm}^{3}$. The design is made of two patches on a single substrate. The patch has $\mathrm{Wp} \times \mathrm{Lp}$ dimension while the outer substrate has $\mathrm{W} \times \mathrm{L}$ dimension. The next resonant mode of antenna is depending on the number of slots in the design. It is fabricated with low cost FR-4 substrate with thickness of $0.6 \mathrm{~mm}$, a dielectric constant of relative permittivity 4.4 and a loss tangent of 0.02 . The proposed tri-band MIMO antenna design parameters are optimized and listed in Table 2. The fabricated tri-band MIMO antenna picture is given in Fig. 2. In this design, we give microstrip feeding by using strip and assign ports.

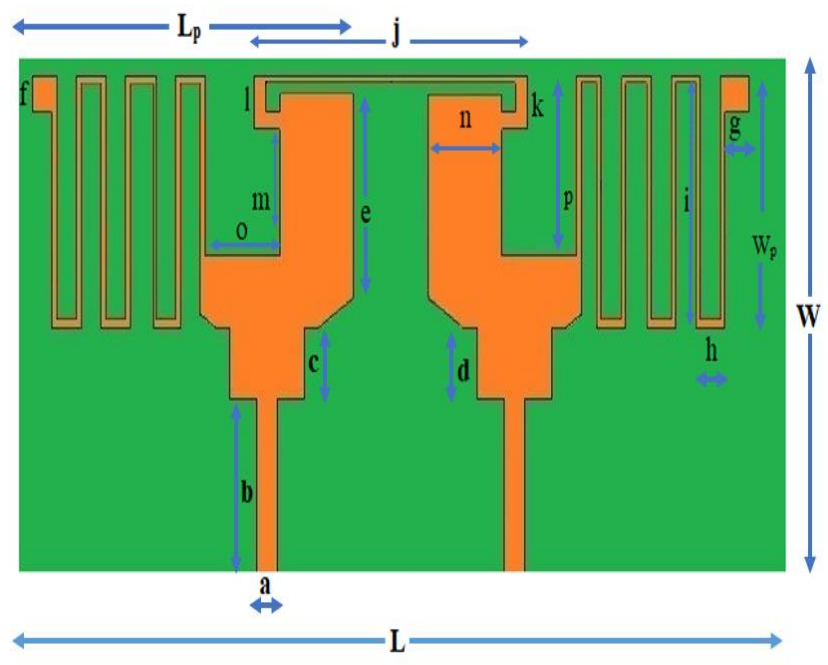

(a)

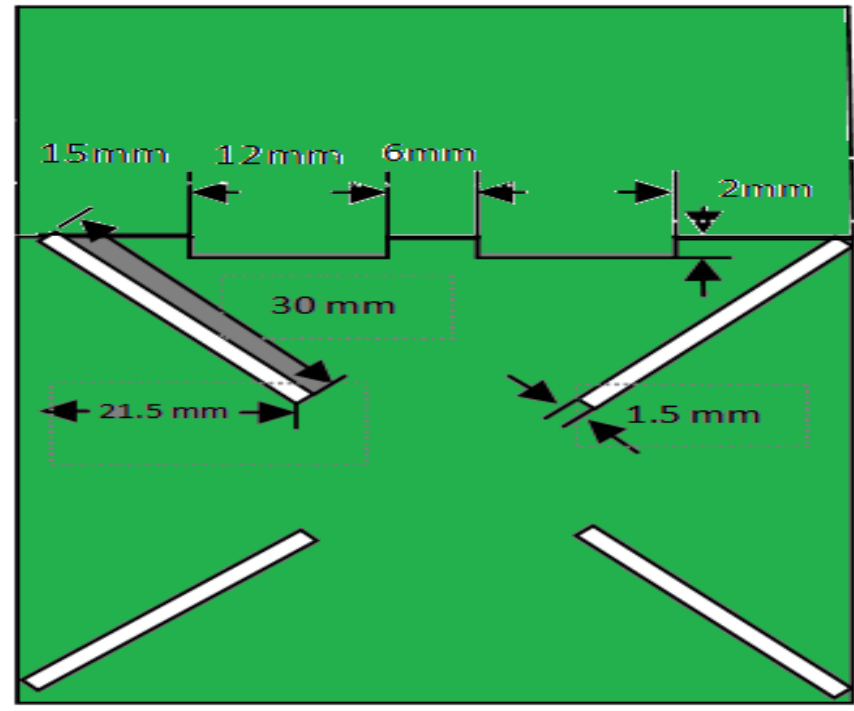

(b)

Fig. 1 Geometry of tri-band MIMO (a) Front view and (b) Rear view

A. Methodology

In this paper a tri-band MIMO antenna is designed using CST software. In order to design an antenna we need to choose dielectric constant value and substrate height. They were chosen as per design frequency. Substrate height is chosen as $0.4 \mathrm{~mm}$.

\section{B. Designing Parameters:}

Calculation of the Width (W)

Effective dielectric constant calculation ( cref $_{\text {) }}$

The Effective length calculation ( $\left.\mathrm{L}_{\mathrm{eff}}\right)$

Length extension parameter calculation $(\Delta \mathrm{L})$

The actual length of patch calculation (L)

$$
\begin{aligned}
& W=\frac{1}{2 f_{r} \sqrt{\mu_{0} \varepsilon_{0}}} \sqrt{\frac{2}{\varepsilon_{r}+1}}=\frac{v_{0}}{2 f_{r}} \sqrt{\frac{2}{\varepsilon_{r}+1}} \\
& \varepsilon_{\text {reff }}=\frac{\varepsilon_{r}+1}{2}+\frac{\varepsilon_{r}-1}{2}\left[1+12 \frac{h}{W}\right]^{-\frac{1}{2}} \\
& L_{\text {eff }}=L+2 \Delta L
\end{aligned}
$$


Table 2: Design parameters of tri-band MIMO antenna design

\begin{tabular}{|c|c|c|c|}
\hline $\begin{array}{l}\text { Design } \\
\text { parameters }\end{array}$ & Value(mm) & $\begin{array}{l}\text { Design } \\
\text { parameters }\end{array}$ & Value(mm) \\
\hline $\mathrm{L}$ & 70 & $\mathrm{f}$ & 3 \\
\hline $\mathrm{W}$ & 50 & $\mathrm{~g}$ & 3 \\
\hline $\mathrm{L}_{\mathrm{P}}$ & 30 & $\mathrm{~h}$ & 2 \\
\hline $\mathrm{W}_{\mathrm{P}}$ & 20 & $\mathrm{i}$ & 2 \\
\hline $\mathrm{a}$ & 3 & $\mathrm{j}$ & 10 \\
\hline $\mathrm{b}$ & 4 & $\mathrm{k}$ & 2 \\
\hline $\mathrm{c}$ & 2 & $\mathrm{l}$ & 3 \\
\hline $\mathrm{d}$ & 2 & $\mathrm{~m}$ & 3 \\
\hline $\mathrm{e}$ & 15 & $\mathrm{n}$ & 4 \\
\hline $\mathrm{p}$ & 10 & $\mathrm{o}$ & 3 \\
\hline
\end{tabular}

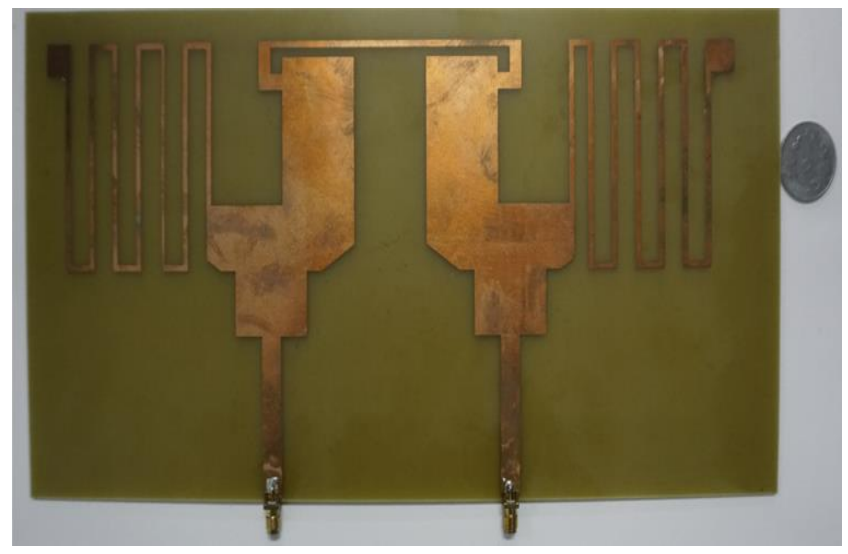

Fig. 2 Fabricated tri-band MIMO antenna design

The location of the feed element with respect to the patch also plays a critical role in the antenna performance. The rectangular slots in upper and lower edge of the patch have been introduced and meander lines are symmetrical and parallel to the $y$-axis have been cut from the main patch. The left and right edge of the patch is embedded with rectangular slots to achieve the required performance by including all the slots added in the design. The feed point is normally located at the ends of patches and the antenna consists of dual radiating elements. A transmission line of $50 \Omega$ feed the antenna coupled by a $1 \mathrm{~mm}$ wide shorting line. The shorting line purpose is neutralize the currents from two elements to increase their isolation. From Fig. 1, four $20 \mathrm{~mm}$ long slits and two $2 \times 12 \mathrm{~mm}^{2}$ rectangles are cut from the rear end of the ground plane for reducing the mutual coupling as well as slightly improving the impedance matching. Here the proposed antenna resonate at three different frequencies, these resonant frequencies are help to useful for enhancing the wider bandwidth of the antenna. In order to developing of this type antenna design environment got good results and with an accuracy values. These values are nearly almost all equal to the measured values but with a minor differences based on type of material used and measurement of parallax error observed.

\section{Multiple Input Multiple Output (MIMO)}

\subsection{Basic Theoretical Concepts}

\subsubsection{Total Active Reflective Coefficient (TARC)}

The ratio of the square root of total reflected power divided by the square root of the incident power is known as the Total Active Reflection Coefficient. The procedure to find TARC by using the mathematical expression

$T A R C=\sqrt{\left|S_{11}+S_{12} e^{j \theta}\right|^{2}+\left|S_{21}+S_{22} e^{j \theta}\right|^{2}} / \sqrt{2}$

Here $\theta$ ranges 0 to $2 \pi$

\subsubsection{Rayleigh Correlation Coefficient}

According to the Rayleigh function, the complex $\rho$ value is obtained by using correlation coefficient $\rho$ for the design MIMO antenna

$$
\rho=\left|\rho_{c i j}\right|^{2}
$$

It is known that, the correlation coefficient consists an array antenna. It represents the effect of propagation paths at different radio frquency signals when it reaches the radiating elements and can be deliberated in two different paths either by using a far-field radiation pattern (3D) or by scattering parameters obtained at the antenna terminals. The measurement and calculation of 3-Dimensional farfield is tedious but by using S-parameters method for computation of the correlation coefficient is used for two antennas. In addition, previous works related to the Sparameters those are well defined which shows the the parameter elements of correlation coefficient represent a closed form of the equation in an array configuration. In addition to the previous work considered by using the Sparameter values represented mathematically in equation (8) at the three resonant frequncies of a $\mathrm{N} \times \mathrm{N}$ antenna system as

$$
\rho(i, j, N)=\frac{\left|\sum_{n=1}^{N} S_{i, n}^{*} S_{n, j}\right|^{2}}{\prod_{k=i, j}\left[1-\sum_{n=1}^{N} S_{k, n}^{*} S_{n, k}\right]}
$$

\subsubsection{The Channel Capacity}

We are moving towards massive MIMO technology for $5 \mathrm{G}$ application and the need to increase high data rate and data throughput are very important. Multiple-input multipleoutput (MIMO) communication technology implements multiple antenna elements on the transmitting and receiving ends of the MIMO system to achieve the aim of maximizing the channel capacity for delivering high data rate traffic in a rich scattering environment. This parameter is related to the amount of information gathering at a channel. The parameter $\mathrm{H}$ is related to channel transformation matrix. The letter $\mathrm{C}$ represents Shannon capacity with a receiver to perform the signal with the help 
of the noisy function. This is a Gaussian distribution is represented by

$$
C=\log _{2}\left(\operatorname{det}\left(I N+\frac{S N R}{M} H H^{\prime}\right)\right)
$$

Here SNR indicates the estimated channel signal to noise ratio

- $\quad \mathrm{I}_{\mathrm{M}}$ represents an identity matrix of order $\mathrm{M}$

- $H^{\prime}$ is the hermitian transpose of the $\mathrm{H}$ matrix (channel coefficient matrix)

- $\quad \mathrm{M}$ is the number of receiving antennas

- $\quad \mathrm{N}$ is the number of transmitting antennas

Here the system consists with $\mathrm{N}$ transmitter and $\mathrm{M}$ receiver antennas. For each transmitting antenna, the process is repeated to obtain the channel matrix $G$. The parameter $G$ describes the notation of $\mathrm{M} \times \mathrm{N}$ and the element $\mathrm{G}_{\mathrm{mn}}$ is the received field at an antenna $n$ while only for transmitting antenna m only. The noise observed is additive Gaussian and assumed to be channel is narrow band with no frequency dependent.

\subsubsection{The Capacity Loss}

The capacity loss is obtained by in the presence of more signals to noise ratio mathematically related by

$$
\begin{aligned}
& C_{\text {loss }}=-\log _{2} \operatorname{det}\left(\Psi^{R}\right)
\end{aligned}
$$

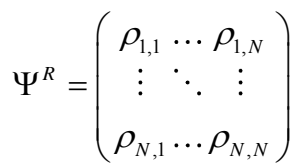

$$
\begin{aligned}
& \Psi^{R}=\left(\begin{array}{l}
\rho_{11} \rho_{12} \\
\rho_{21} \rho_{22}
\end{array}\right) \\
& \rho_{11}=1-\left(\left|S_{i i}\right|^{2}+\left|S_{i j}\right|^{2}\right) \quad \rho_{i j}=-\left(S_{11}^{*} S_{i j}+S^{*}{ }_{j i} S_{j j}\right) \\
& \text { for } \mathrm{i}, \mathrm{j}=1 \text { or } 2
\end{aligned}
$$

Where $\Psi^{\mathrm{R}}$ is the receiving antenna correlation matrix

Table 3: Contrast of Tri-band MIMO antenna design parameters at different frequencies

\begin{tabular}{|c|l|l|l|l|l|}
\hline $\begin{array}{l}\text { S.No } \\
\cdot\end{array}$ & $\begin{array}{l}\text { Frequen } \\
\text { cy } \\
(\mathrm{GHz})\end{array}$ & $\begin{array}{l}\text { Correlati } \\
\text { on } \\
\text { coefficie } \\
\text { nt }(\rho)\end{array}$ & $\begin{array}{l}\text { TARC } \\
(\mathrm{dB})\end{array}$ & $\begin{array}{l}\text { Channel } \\
\text { Capacity } \\
\text { (bits/s/H } \\
\mathrm{z})\end{array}$ & $\begin{array}{l}\text { Capacity } \\
\text { Loss in } \\
\text { (bits/s/H } \\
\text { z) }\end{array}$ \\
\hline 1 & 3.5 & 0.0014 & -19.63 & 3.097 & 0.57 \\
\hline 2 & 5.3 & 0.0018 & -22.87 & 4.015 & 0.46 \\
\hline 3 & 7.0 & 0.0036 & -29.45 & 4.057 & 0.32 \\
\hline
\end{tabular}

From the Table 3, observed that the importance of MIMO parameters represents the entire bandwidth frequency range from $2 \mathrm{GHz}-10 \mathrm{GHz}$ at three resonant bands frequency is operated in different applications. In this design the channel capacity at a frequency of $3.5 \mathrm{GHz}$ is 3.097 bits $/ \mathrm{s} / \mathrm{Hz}$, the frequency at $5.3 \mathrm{GHz}$ is $4.015 \mathrm{bits} / \mathrm{s} / \mathrm{Hz}$ and at another frequency at $7.0 \mathrm{GHz}$ is $4.057 \mathrm{bits} / \mathrm{s} / \mathrm{Hz}$.

\section{4. $\quad$ Results \& Discussion}

The tri-band MIMO prototype antenna is experimentally tested by vector network analyzer consist a number R\&S ZVA 40. Fig. 3 depicts the comparison of simulated and measured result of return loss, $\mathrm{S}_{11}$ against frequency along with its fabricated photograph. Fig. 4 shows the contrast of simulated result and measured result of mutual coupling, $\mathrm{S}_{12}$ against frequency along with its fabricated photograph. Fig. 5 depicts the comparison of result consist using simulation and result consist using measured of Sparameters against frequency along with its fabricated photograph. Fig. 6 depicts the contrast of simulated result and measured result of VSWR against frequency along with its fabricated photograph. Fig. 7 depicts the distribution of surface current of tri-band MIMO antenna radiating element at three different resonant frequency at (a) $3.5 \mathrm{GHz}$, (b) $5.3 \mathrm{GHz}$ and (c) $7.0 \mathrm{GHz}$. We observed that the bandwidths of measured impedance about 500 $\mathrm{MHz}(3.2-3.7 \mathrm{GHz}), 500 \mathrm{MHz}(5.1-5.6 \mathrm{GHz})$ and 800 $\mathrm{MHz}(6.7-7.5 \mathrm{GHz})$. It is observed that the simulated results and measured results are showed reasonable good agreement. The following bandwidths are used for these particular bands of tri-band antenna appropriate to Wireless LAN, 3.5 GHz WiMAX, 5.3 GHz and 7.0 GHz defence system \& radio astronomy. The discrepancies in measured and simulated results might vary in relation to tolerance of fabrication process, undetermined value of FR-4 substrate, undetermined dielectric constant of the FR-4 substrate and working condition of SMA connector used. The important parameters to be considered for any MIMO system are channel capacity, correlation coefficient $(\rho)$, Total Active Reflection coefficient (TARC) and channel capacity loss. These parameters are calculated by using the equations (6) to (13).

The parameters of channel capacity, capacity loss, TARC and correlation coefficient is shown in Table 3. Here a neutralizing line and four slits are made onto to the ground plane, inserted in the middle of dual antennas that generates an isolation is below the $-20 \mathrm{~dB}$ in the entire operating frequencies. Here the proposed tri-band MIMO antenna got good result in comparison to other reference methods. Fig. 3 shows the characteristics of the measured results and simulated results of input reflection coefficient $\left|\mathrm{S}_{11}\right|$ of the proposed antenna, and a relative good agreement in between simulation and measurement can be observed. It is noticed that the input impedance of the fabricated antenna performs well in the three operating frequency bands which covers the Wireless LAN 3.5 GHz, WiMAX $5.3 \mathrm{GHz}$ and defence system \& radio astronomy 7.0 GHz with $\left|\mathrm{S}_{11}\right|<-10 \mathrm{~dB}$. 


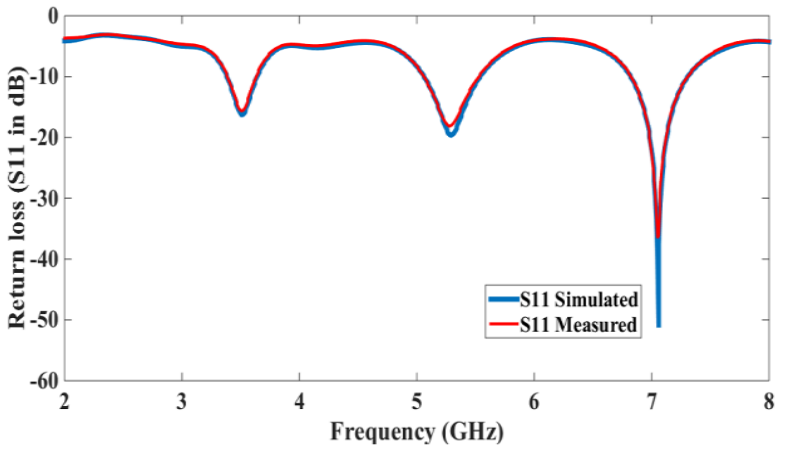

Fig. 3 Return loss picture of design tri-band antenna

This antenna working mechanism was improved upon by using the four slits and neutralizing line in design of triband MIMO antenna, Fig. 4 depicts the measured results and simulated results of $\left|S_{12}\right|$ parameter of MIMO antennas with different decoupling configurations. It can be found that the mutual coupling $\left(\mathrm{S}_{12}\right)$ deteriorates seriously in the three resonant operating bands when MIMO antenna without neutralizing line and four slits is used. The isolation is greatly improved in the WiMAX $5.3 \mathrm{GHz}$ and 7.0 $\mathrm{GHz}$ defence system \& radio astronomy applications when MIMO antenna with neutralizing line. Moreover, the coupling can be further decreased in the WLAN $3.5 \mathrm{GHz}$ band when MIMO antenna with four slits is etched into the rear end of ground plane. Fig. 4 presents the measured results and simulated results of mutual coupling $\left|\mathrm{S}_{12}\right|<-30$ $\mathrm{dB}$ is in the service frequencies covering WLAN, WiMAX and defence system \& radio astronomy bands with both neutralizing line and four slits. Fig. 5 represents the comparison of scattering parameters for the entire band of operating frequencies form $2.0-8.0 \mathrm{GHz}$ which resonant at three different frequencies. It could have been clearly seen that at resonance frequency of $3.5 \mathrm{GHz}$ at first stage, 5.3 $\mathrm{GHz}$ at second stage and $7 \mathrm{GHz}$ at third stage resonant frequency, the mutual coupling improvement observed -55 $\mathrm{dB},-42.5 \mathrm{~dB}$ and $-58 \mathrm{~dB}$ were achieved respectively. Further, at the third resonant frequency $(7.5 \mathrm{GHz})$, a great improvement in isolation as well as reflection coefficient, $\mathrm{S}_{11}$ of $-49 \mathrm{~dB}$ is observed. Fig. 6 shows the measurement of VSWR comparison between measured and simulated values are VSWR $\leq 2$ for the entire band at three resonant frequencies. The parameter of channel capacity is measured in the entire band of frequency range is depict in Fig.7

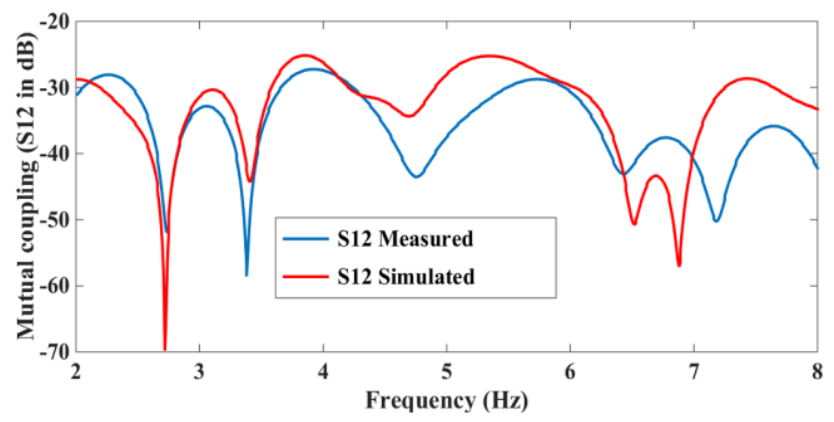

Fig. 4 Mutual coupling picture of tri-band antenna

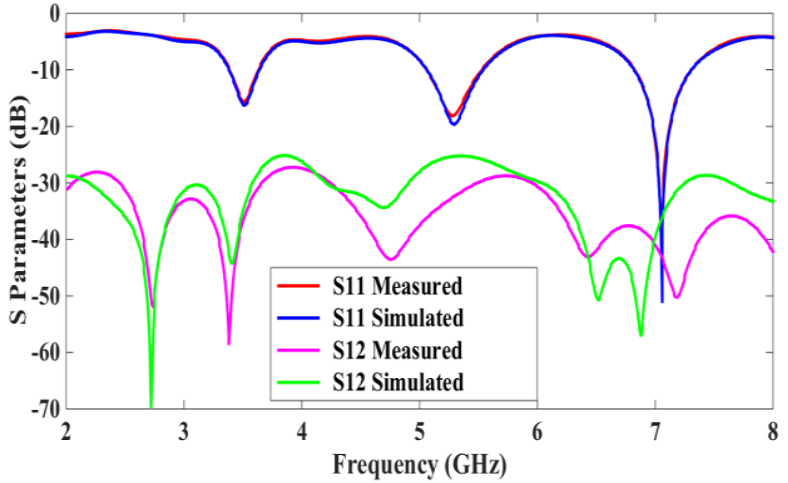

Fig. 5 S-parameters results of tri-band antenna

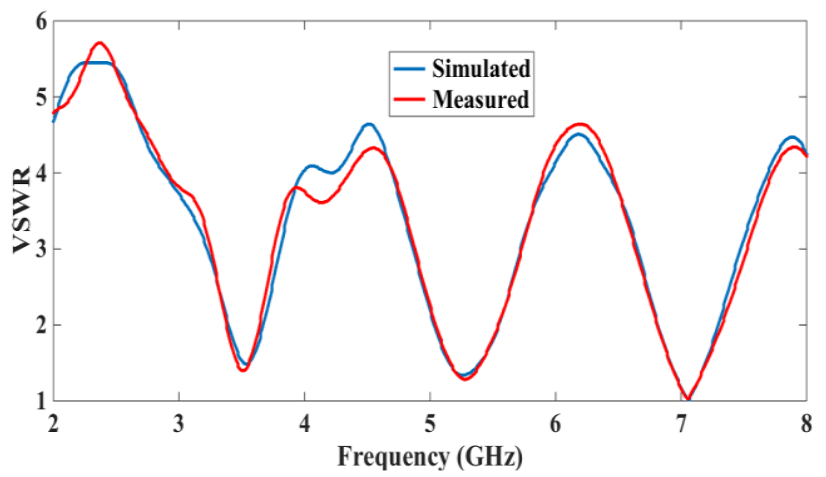

Fig. 6 VSWR values of tri-band antenna

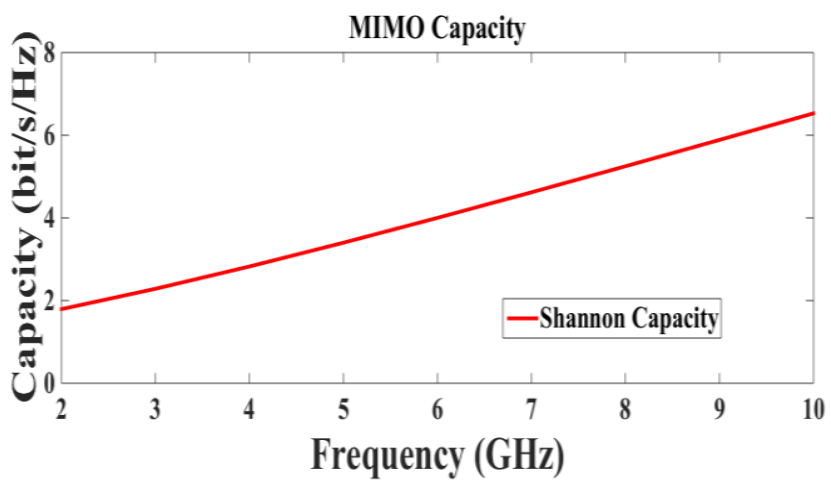

Fig. 7 Channel capacity of tri-band antenna

By analysing the surface current distribution from Fig. 8 the mutual coupling reduction between the antennas is arrived at and the shape of tri-band MIMO antenna is decided upon. Depending on the directions of the current flowing on the surface of the antennas, the extent of mutual coupling that is needed between dual antennas in a MIMO system design is decided. When the dual antenna are placed adjacent to each other current flow is observed to be maximum and in the same direction as that of the isolation. The induced isolation is minimized when current flows in opposite direction. From Fig. 8 depicts the current flowing in opposite directions in tri-band MIMO antenna represents the surface current distribution on right hand side of the first radiator when patch placed in between proposed dual band antennas thus minimizing the mutual coupling. As shown in Fig. 8(a), the currents are flowing in an upward 
direction when the neutralizing line is excited. On the other side, when the currents are flowing in circular loop-the four slits in the antenna are excited as depicts in Fig. 8(b). By using this type of arrangement both resonant modes to exist simultaneously as well as independently of each other, resulting in low amount of mutual coupling is observed. In Fig. 8(b), it is observed that high amount of surface current gets at the four slits of the microstrip feed line. In Fig. 8(c), partial concentration of current flows can be observed in four slits and neutralizing line. Similarly, current flow is equal in the three resonant frequencies at port 2 also. The tri-band MIMO antenna at port 1 represents nil net current being flown when the surface current at right arm side and left arm side of the radiator is being flown to lead opposite direction. By using this type of arrangement in the tri-band MIMO antenna a good mutual coupling is achieved in between the Port 1 and Port 2 .

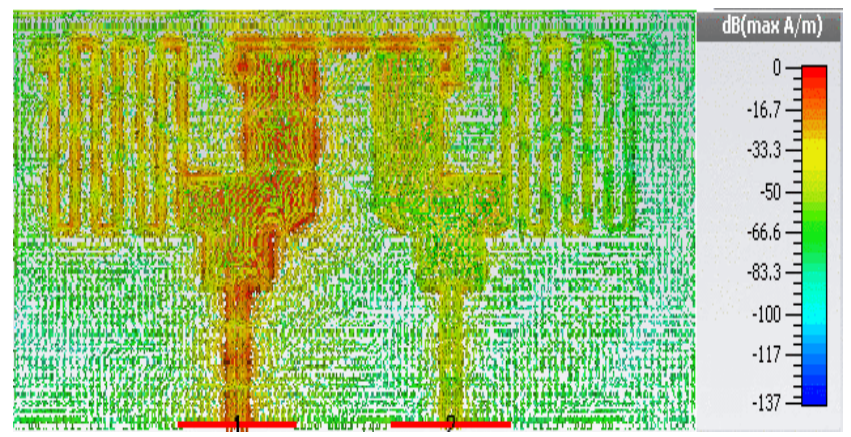

(a) Frequency at $3.5 \mathrm{GHz}$

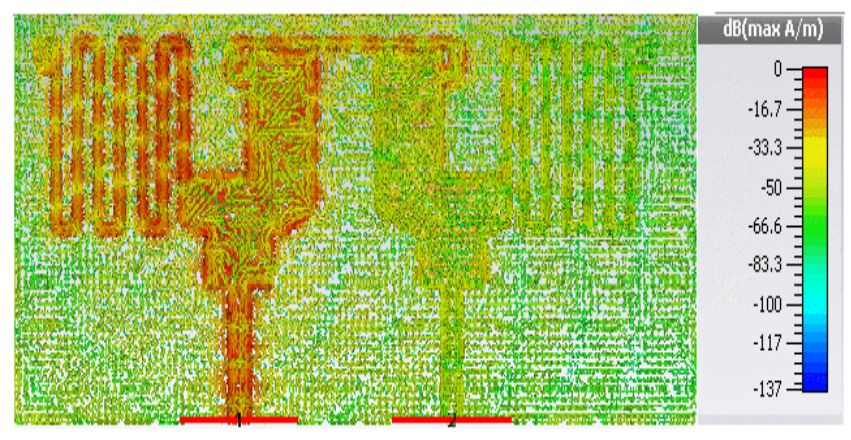

(b) Frequency at $5.3 \mathrm{GHz}$

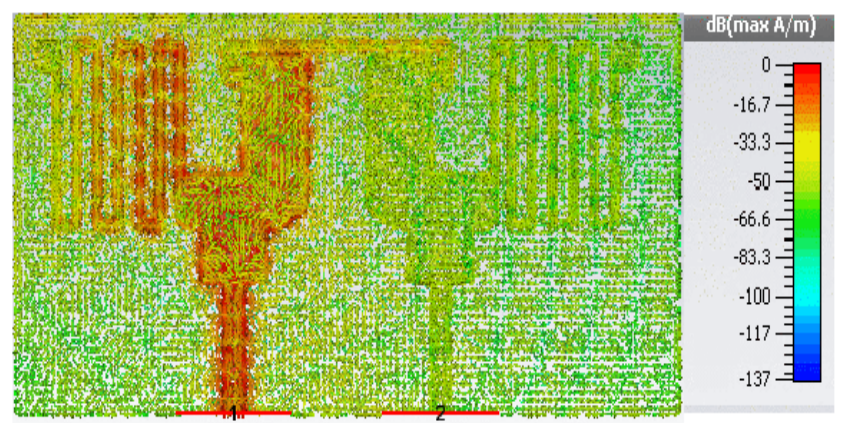

(c) Frequency at $7.0 \mathrm{GHz}$

Fig. 8 Surface current distribution of tri-band antenna with frequency at (a) $3.5 \mathrm{GHz}$ (b) $5.3 \mathrm{GHz}$ and (c) $7.0 \mathrm{GHz}$
The radiation patterns of tri-band MIMO antenna are simulated using Computer Simulation Technology and measured results in an in-house anechoic chamber using an antenna measurement trainer system. A caliber double ridged horn radiator is used as a reference antenna. When one port is excited and the other port is terminated by a 50 $\Omega$ load. The simulated result and measured result radiation patterns of the tri-band MIMO patch antenna are depicts in Fig. 9(a) - 9(c) for different frequencies $(3.5 \mathrm{GHz}, 5.3$ $\mathrm{GHz}$, and $7.0 \mathrm{GHz}$ ). The nature of H-plane radiation patterns is omnidirectional and observed bi-directional (dumb-bell shaped) radiation pattern of E-plane. For both cases, simulated results as well as measured results noticed be closely approximated but a small variations observed to measuring as well as alignment errors.

In E-plane radiation pattern is nearly monopole and in $\mathrm{H}$ plane radiation pattern is omnidirectional. It makes the triband MIMO antenna is a better choice for Wireless LAN, 3.5 GHz WiMAX, 5.3 GHz and 7.0 GHz defence system \& radio astronomy. The efficiency of tri-band MIMO antenna at frequency of $3.5 \mathrm{GHz}, 5.3 \mathrm{GHz}$ resonant frequency, and final frequency at $7.0 \mathrm{GHz}$ is evaluated using Computer Simulation Technology. The radiation efficiency of the proposed structure is measured the combination of radiation resistance involved as well as loss resistance of the antenna involved in the design procedure of the antenna analysis. From the tri-band MIMO got the efficiencies are 82,83 , and $89 \%$.

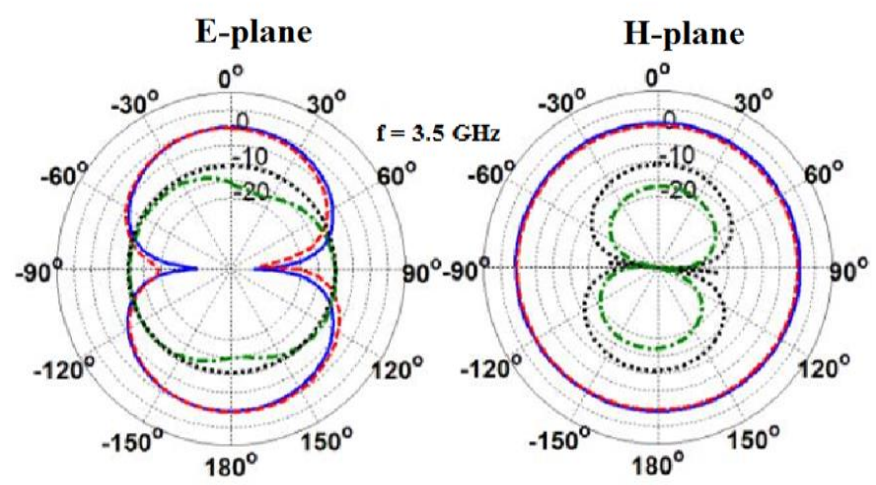

(a) Frequency at $3.5 \mathrm{GHz}$

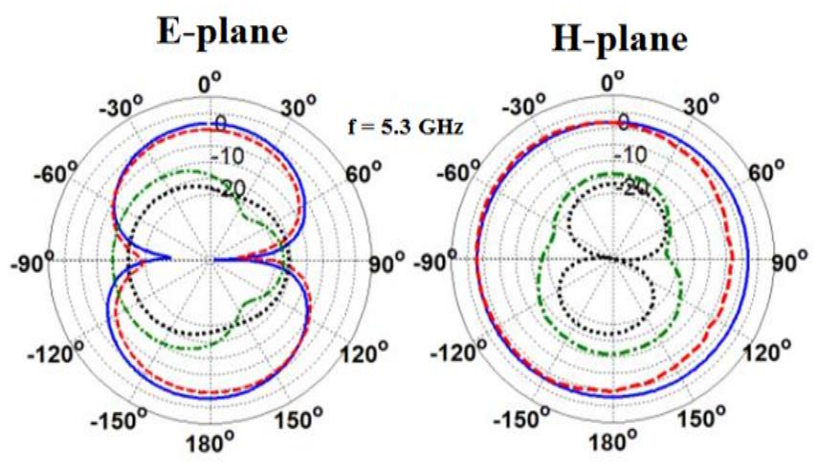

(b) Frequency at $5.3 \mathrm{GHz}$ 


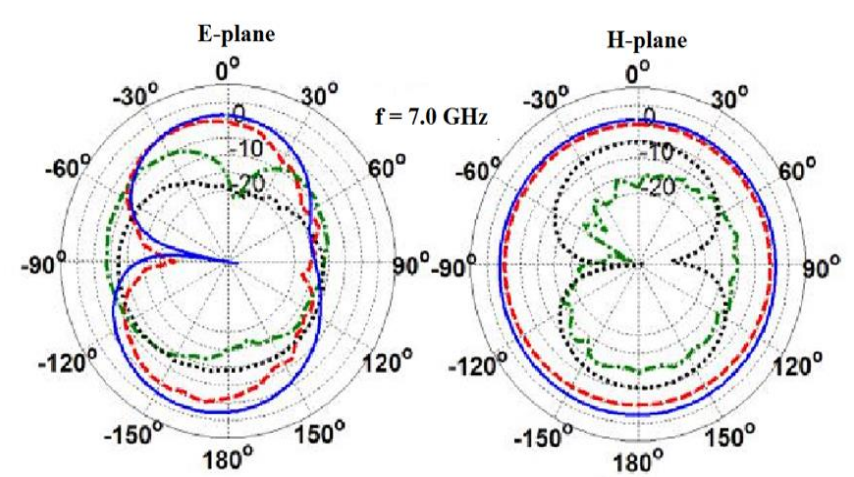

(c) Frequency at $7.0 \mathrm{GHz}$

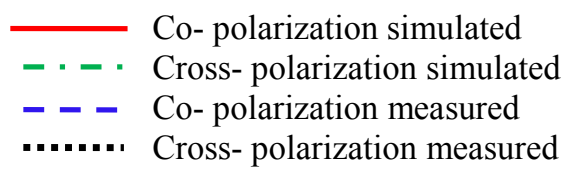

Fig. 9 Measured and simulated radiation patterns of the proposed tri-band antenna at (a) $3.5 \mathrm{GHz}$, (b) $5.3 \mathrm{GHz}$ and (c) $7.0 \mathrm{GHz}$

\section{CONCLUSION}

A unique tri-band MIMO patch antenna for WLAN, WiMAX and defence system \& radio astronomy applications has been proposed in this paper. Using beveled rectangular metal patches and folded monopole as the antenna element, the characteristic of tri-band is realized. High mutual coupling $\left|\mathrm{S}_{12}\right|<-30 \mathrm{~dB}$ in the entire band of frequency range from $2.0-8.0 \mathrm{GHz}$ is achieved by using the method of neutralizing line and cutting four slits in the back ground plane. The results of scattering parameters, radiation pattern, VSWR, channel capacity, TARC and envelope correlation coefficient are presented. Likewise, to test the performance of tri-band MIMO antenna in the real-time applications of WLAN, WiMAX and defence system, the base stations with three kinds of antenna feed systems are constructed. The tri-band MIMO antenna can be potential game changer for WLAN, WiMAX and defence system \& radio astronomy applications.

\section{References}

[1] Sharma MM, Deegwal JK, et al, "Compact printed ultra-wideband antenna with two notched stop bands for WiMAX and WLAN," International Journal of Applied Electromagnetism., vol. 47(2), 523-32, 2015.

[2] Xiu Yin Zhang, Yao Zhang, et al, "Low-Profile DualBand Filtering Patch Antenna and Its Application to LTE MIMO System," IEEE Trans. on Ant. \& Prop., vol.65(1), 103-113,2017.

[3] Gunjan S and Akhilesh M, "Compact MIMO Slot Antenna for UWB Applications," IEEE Ant. \& Wireless Prop. Lett., vol. 15, 1057-1060, 2015.

[4] Li Z, Du Z, Takahashi M, et al, "Reducing mutual coupling of MIMO antennas with parasitic elements for mobile terminals," IEEE Trans Antennas and Propagation., vol. 60(2), 473-1, 2012.

[5] Su SW, Lee CT, et al, "Printed MIMO-antenna system using neutralization-line technique for wireless USBdongle applications," IEEE Trans Antennas and Propagation., vol. 60(2), 456-3, 2012.

[6] Ghosh Chandra Kumar, et al, "A compact 4-channel microstrip MIMO antenna with reduced mutual coupling," AEU International Journal of Electronics Communication.,vol.40(2),538-4,2016. http://dx.doi.org/10.1016/j.aeue.2016.03.018.

[7] Liu L, Cheung SW, et al, "Compact MIMO antenna for portable devices in UWB applications,"IEEE Trans Antennas and Propagation., vol. 61(8), 4257-4, 2013.

[8] Liu L, Cheung SW, et al, "Compact MIMO antenna for portable UWB applications with band-notched characteristic," IEEE Trans Antennas and Propagation., vol. 63(5), 1917-4, 2015.

[9] Sipal D, Abegaonkar MP, et al, "Compact bandnotched UWB antenna for MIMO applications in portable wireless devices," Microwave Opt Technology Letters., vol. 58(6),1390-4, 2016.

[10] Zhu J, Feng B, et al, "Dual notched band MIMO slot antenna system with Y-shaped defected ground structure for UWB applications," Microwave Opt Technology Letters., vol. 58(3),626-30, 2016.

[11] Luo CM, Hong JS, et al, "Isolation enhancement of very compact UWB-MIMO slot antenna with two defected ground structures,"IEEE Antennas Wireless Propagation Letters., vol. 14, 1766-9, 2015.

[12] Khan MS, Capobianco AD, et al, "An Ultra Compact Dual-Polarised UWB MIMO Antenna with meandered Feeding Lines,'IET Microwaves, Antennas and Propagation., vol. 12,547-3, 2017.

[13] Li Z, Du Z, Takahashi M, et al, "Reducing mutual coupling of MIMO antennas with parasitic elements for mobile terminals," IEEE Trans Antennas and Propagation vol.60(2),473-1.2012

[14] Su SW, Lee CT, et al, "Printed MIMO-antenna system using neutralization-line technique for wireless USBdongle applications," IEEE Trans Antennas and Propagation. vol. 60(2), 456-3, 2012.

[15] Liu L, Cheung SW, et al, "Compact MIMO antenna for portable devices in UWB applications," IEEE Trans Antennas and Propagation., vol. 61(8), 4257-4, 2013.

[16] Liu L, Cheung SW, et al, "Compact MIMO antenna for portable UWB applications with band-notched characteristics,"IEEE Trans Antennas and Propagation., vol. 63(5), 1917-4, 2015.

[17] Li JF, Chu QX, et al, "Compact dual band-notched UWB MIMO antenna with high isolation," IEEE Trans Antennas and Propagation., vol. 61(9), 4759-6, 2013.

[18] Khan MS, Iftikhar, et al, "Ultra Compact DualPolarised UWB MIMO Antenna with meandered Feeding Lines," IET Microwaves, Antennas \& Propagation., vol. 78(7),2345-3,2017.

http://digitallibrary.theiet.org/content/journals/10.1049/ietmap.2016.1074.

[19] A. Toktas, A. Akdagli, "Wideband MIMO Antenna with enhanced isolation for LTE, WiMAX and WLAN 
mobile handsets," Electronic Letters., vol. 50(9), 723-724, 2014.

[20] S. Park, C. Jung, "Compact MIMO antenna with high isolation performance," Electronic Letters., vol. 46(6), 390391, 2010.

[21] P.S. Kildal, K.Rosengram, "Correlation and capacity of MIMO systems and coupling, radiation efficiency, diversity gain of their antennas," IEEE Communication, Magnetics., vol. 42(12), 102-112, 2004

[22] Zhang, S., Lau, B. K., et al, "Closely-packed UWB MIMO/diversity antenna with different patterns and polarizations for USB dongle applications," IEEE Trans. Antennas Propagation., vol. 60(9), 4372-4380, 2015

[23] Ryan, C. G. M., et al, "Two Compact, Wideband, and Decoupled Meander-Line Antennas Based on Metamaterial Concepts," IEEE Antennas and Wireless Propagation Letters., vol. 11(4), 1277-1280, 2012.

[24] Khan, M. S. Capobianco, et al, “A Compact Dual Polarized Ultra Wideband Multiple-Input Multiple-Output antenna," Microwave Optical and Technology Letters., vol. 58(1), 163-166, 2016.

[25] Z. Zainal Abidin, R.A. Abd-Alhameed, et al, "Design and Analysis of UC-EBG on mutual coupling Reduction," Loughborough Antennas \& Propagation Conference., 9781-4244-2721-5,2009

[26] Z. Z. Abidin, Y. Ma, R. A. Abd-Alhmeed, et al, "Design of 2 × 2 U shape MIMO slot antennas with EBG material for mobile handset applications," Progress in Electromagnetic Research., vol. 7(1), 2011.

[27] Li, J.-F., et al, "A compact wideband MIMO antenna with two novel bent slits," IEEE Transaction on Antennas \& Propagation., vol. 60(2), 482-489, 2012. 